\title{
Complex nasal reconstruction after paracoccidioidomycosis infection - Case report*
}

\author{
Emilie Barreto Ribeiro ${ }^{1}$ \\ Eduarda Nilo de Magaldi ${ }^{1}$ \\ Nivaldo Alonso ${ }^{2}$
}

\author{
Victor Diniz de Pochat ${ }^{1}$ \\ Bruno Suffredini Figueiredo ${ }^{1}$ \\ José Valber de Lima Meneses ${ }^{1}$
}

DOI: http:/ / dx.doi.org/10.1590/abd1806-4841.20153527

\begin{abstract}
A bstract: Paracoccidioidomycosis is an infectious disease whose etiological agent belongs to the Paracoccidioides genus. Although it affects primarily the lungs, it can spread to other tissues, including the skin and mucous membranes. Despite the clinical treatment for this disease, scarring can produce sequelae, manifesting as anatomical and functional deformities of the face. We present a case of extensive, nasal unaesthetic and functional sequelae resulting from paracoccidioidomycosis, reconstructed using the paramedian forehead flap in three stages, through the regional unit principles.
\end{abstract}

Keywords: Forehead; Nose deformities, acquired; Paracoccidioidomycosis; Reconstruction; Surgical flaps

\section{INTRODUCTION}

Paracoccidioidomycosis is a systemic infectious disease occurring in tropical and subtropical areas. The endemic center of this diseaseis Brazil. Its etiologicagent belongs to the Paracoccidioides genus and primarily affects the lungs through inhalation of the fungus, but it also has the potential to spread to other tissues, including the skin and mucosa. 1,2 Skin lesions result from hematogenous dissemination, contiguous preexisting injury or, very rarely, from direct inoculation of the fungus into the skin; thus, superficial wounds have variable aspects, such as papules, ulcerations, crusting or granulomatous appearance. ${ }^{3,4}$ Although treatment for this disease is clinical, scarring can produce sequelae, manifesting as anatomical and functional deformities in the face, oropharynx and lungs. ${ }^{2,5}$ The aim of this study is to report a case of extensive, nasal unaesthetic and functional sequelae after paracoccidioidomycosis, affecting the right ala, nasal sidewall, nasal tip, dorsum as well as the underlying lining. We also describe repair procedures, using the paramedian forehead flap in three stages, based on the regional unit principles.

\section{CASE REPORT}

A 28-year-old male, with a history of painful ulcerated skin lesions in the neck, forehead, chin, nose and lip, associated with fever and asthenia, received the diagnosis of paracoccidioidomycosis, confirmed through a biopsy of the skin lesions. After two years, he noticed a single acneiform lesion on the right ala, painless at first, evolving into a painful ulcerated lesion of irregular and asymmetrical shape, affecting the right nasal ala (full thickness), associated with purulent and bloody secretion. Although the patient presented regression of lesions after drug treatment with amphotericin B plus trimethoprimsulfamethoxazole, he developed nasal sequelae with complete loss of the right ala, scar retraction of the tip, columella and right sidewall, and ipsilateral nostril stenosis (Figure 1).

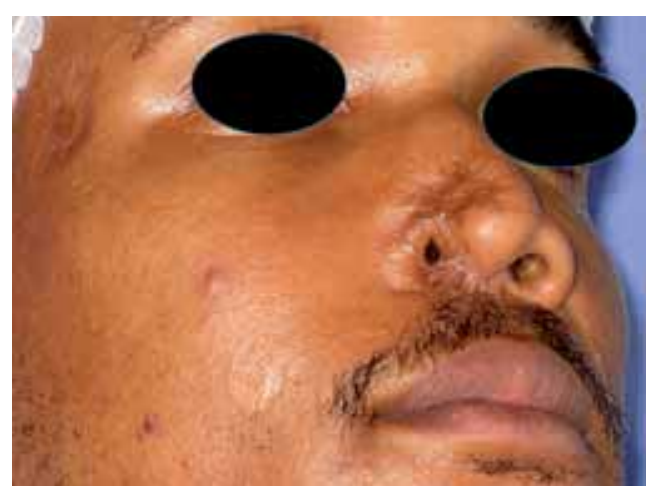

Figure 1: Preoperative view of nasal deformity, secondary to paracoccidioidomycosis, with stenosis in the right nostril 
The patient underwent a prior surgical procedure for correction of nostril stenosis with local flaps and a small skin graft (Figure 2). Afterwards, nasal reconstruction with a forehead flap was performed in three stages. During the first, nasal lining was repaired using a hingeover flap and a folded, full thickness paramedian forehead flap. To support and contour the defect, the right ala and right sidewall were supported and shaped by an ear cartilage graft, while the tip was supported by a collumelar strut and an onlay tip graft (Figure 3). Based on a template (exact pattern), the paramedian forehead flap was planned and elevated to cover both the missed skin and lining (Figure 4). In an intermediate operation (second stage), three weeks later, the forehead skin was elevated with $3 \mathrm{~mm}$ of subcutaneous fat from the alar margin (the distal folded skin lining was integrated into the residual adjacent lining). After three weeks, we performed the pedicle division, the third stage (Figure 5). All surgeries were performed under general anesthesia.

\section{DISCUSSION}

Transmission of paracoccidioidomycosis occurs mainly through inhalation of the agent. It is a disease of polymorphic presentation and it can vary from isolated soft tissue injuries to clinically disseminated disease. ${ }^{3,6,7}$ Over $90 \%$ of affected patients are males

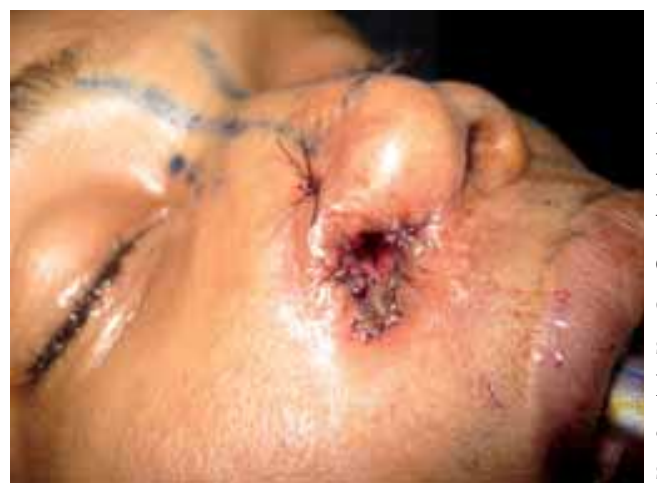

Figure 2: Immediate postoperatory view after correction of nostril stenosis with local flaps and a small skin graft

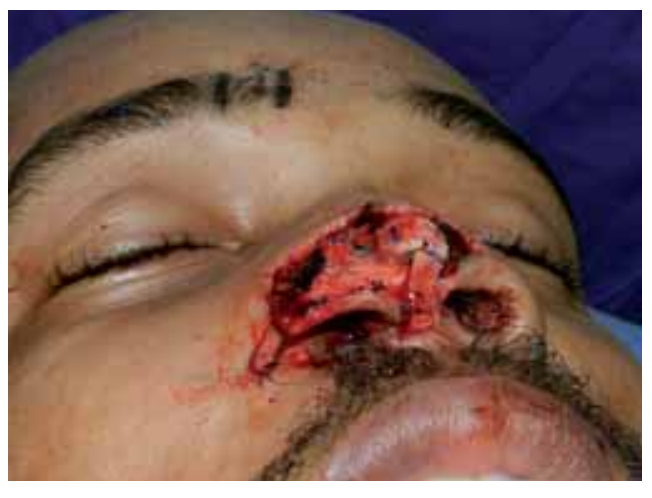

FIGURE 3: Primary ear cartilage grafts for nasal support and shaping

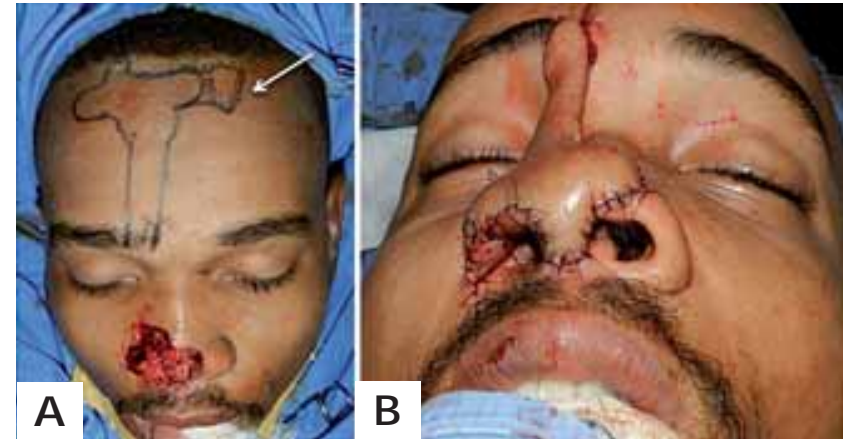

Figure 4: A. Exact pattern of the paramedian forehead flap, designed for covering and lining (white arrow);

B. Immediate postoperative view after the first stage (flap transferred)

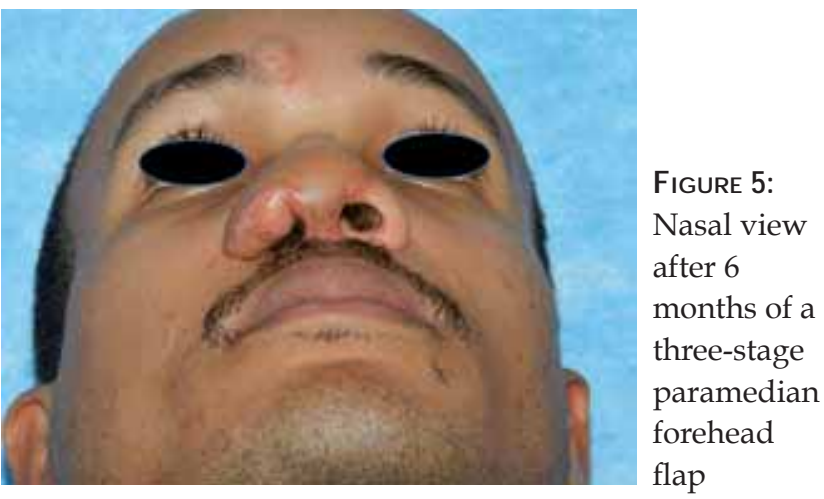

and individuals aged 30-50 are the most affected age group. ${ }^{4}$ The prevalence of skin lesions varies in the literature from $30 \%$ to $54.2 \%$. ${ }^{1}$ Marques et al. studied a sample of 152 patients and realized that the face was the site most affected by skin lesions and that the ulcerated pattern was predominant. ${ }^{1}$ Despite adequate response to clinical treatment, the healing process may be associated with some degree of fibrotic scarring, which can result in unaesthetic sequelae and functional impairment of the affected tissue. ${ }^{7}$

The forehead flap was first used in India a thousand years BC and, even nowadays, it is considered the procedure of choice for reconstructing extensive nasal defects. The color and texture of the skin on the forehead are the reason why this is the best donor site for nasal restoration. This flap can be carried out in one, two or three stages and potentially involves subsequent surgical refinements. 8,9

Obtaining a truly satisfactory result in nasal reconstruction requires dedication and persistence by the plastic surgeon, as well as tolerance from patients. The decision to perform reconstruction with the forehead flap in three stages (with a prior surgery) 
in this case is related to the complexity of the injury. Menick ${ }^{8}$ described numerous advantages resulting from the inclusion of an intermediate stage. In addition to the texture, color and contour of the skin coverage, the concept of regional nasal units (tip, alas, sidewalls, collumela, dorsum and soft triangle) is of great importance to obtain a satisfactory result. Burget and Menick proposed the removal of all the remaining portion of subunit in case of losses above $50 \%$, followed by reconstruction of the subunit as a whole. ${ }^{10}$ The goal is to camouflage scars along the edges of each subunit.

We emphasize that in the case discussed, further revision will be needed in order to achieve a better, three-dimensional outcome

\section{REFERENCS}

1. Marques SA, Cortez DB, Lastória JC, de Camargo RMP, Marques MEA Paracoccidioidomycosis: Frequency, Morphology, and Pathogenesis of Tegumentary Lesions. An Bras Dermatol. 2007;82:411-7.

2. Palmeiro M, Cherubini K, Yurgel LS. Paracoccidioidomicose: revisão da literatura. Scientia Medica PUCRS. 2005;15:274-8.

3. Restrepo A, Robledo M, Giraldo R, Hernández H, Sierra F, Gutiérrez F, et al. The gamut of paracoccidioidomycosis. Am J Med. 1976;61:33-42.

4. Shikanai-Yasuda MA, Telles Filho Fde Q, Mendes RP, Colombo AL, Moretti ML. Guideliness in paracoccidioidomycosis. Rev Soc Bras Med Trop. 2006;39:297-310.

5. Marques SA. Paracoccidioidomycosis: epidemiological, clinical, diagnosis and treatment up-dating. An Bras Dermatol. 2013;88:700-11.

6. Ramos-E-Silva M, Saraiva Ldo E. Paracoccidioidomycosis. Dermatol Clin. 2008;26:257-69, vii.

7. Rocha GJNM, Nossa LMB, Pinto MR, MarbackRL. Palpebral paracoccidioidomycosis: report of three cases. Arq Bras Oftalmol. 2002;65:575-8.

8. Fudem GM, Montilla RD, Vaughn CJ. Single-stage forehead flap in nasal reconstruction. Ann Plast Surg. 2010;64:645-8

9. Menick FJ. A 10-year experience in nasal reconstruction with the three-stage forehead flap. Plast Reconstr Surg. 2002;109:1839-55.

10. Burget GC, Menick FJ. The subunit principle in nasal reconstruction. Plast Reconstr Surg. 1985;76:239-47.
M AILING ADDRESS:

Emilie Barreto Ribeiro

Rua A ugusto Viana

Canela

40110-060 Salvador, BA.

Brazil

E-mail: emilieribeiro@hotmail.com

H ow to cite this article: Ribeiro EB, Pochat VD, Magaldi E, Figueiredo BS, Alonso N, Meneses JVL. Complex nasal reconstruction after paracoccidioidomycosis infection - Case report. An Bras Dermatol. 2015;90(3 Supl 1):S203-5. 